\title{
Modulation of Phosphodiesterase6 Turnoff during Background Illumination in Mouse Rod Photoreceptors
}

\author{
Michael L. Woodruff, ${ }^{1}$ Kerstin M. Janisch, ${ }^{2}$ Igor V. Peshenko, ${ }^{3}$ Alexander M. Dizhoor, ${ }^{3}$ Stephen H. Tsang, ${ }^{2}$ and \\ Gordon L. Fain ${ }^{1,4}$ \\ ${ }^{1}$ Department of Physiological Science, University of California Los Angeles, Los Angeles, California 90095-1606, 2Brown Glaucoma Laboratory, Department \\ of Pathology and Cell Biology, College of Physicians and Surgeons, Columbia University, New York, New York 10032, ${ }^{3}$ Hafter Research Laboratories, \\ Pennsylvania College of Optometry, Elkins Park, Pennsylvania 19027, and ${ }^{4}$ Jules Stein Eye Institute, University of California Los Angeles School of \\ Medicine, Los Angeles, California 90095-7000
}

In rod photoreceptors of wild-type mice, background light produces an acceleration of the decay of responses to brief flashes, accompanied by a decrease in the rate-limiting time constant for response decay. In rods in which phosphodiesterase $\gamma(\operatorname{PDE} \gamma)$ lacks one of its sites of phosphorylation (T35A rods), both the waveform of response decay and the rate-limiting time constant are nearly unaffected by backgrounds. These effects are not the result of the removal of the phosphorylation site per se, because rods lacking both of the phosphorylation sites of $\mathrm{PDE} \gamma$ (T22A/T35A rods) adapt to light in a nearly normal manner. Because PDE $\gamma$ is one of the proteins of the GTPase activating protein (GAP) complex, our experiments argue for a novel mechanism of photoreceptor light adaptation produced by modulation of GAP-dependent hydrolysis of transducin $\alpha$ GTP. In PDE $\gamma$ T35A rods, a change in the conformation of the PDE $\gamma$ subunit may hinder or mask this mechanism, which in mammals appears to be primarily responsible for the quickening of the temporal resolution of the rod response in backgrounds. Modulation of PDE turnoff also helps to prevent premature saturation of the rod in bright backgrounds, thus making an important contribution to light adaptation. Our experiments provide evidence for modulation of GAP protein-dependent response turnoff, which may also play a role in controlling signal duration at hormone receptors and synapses in the CNS.

Key words: photoreceptor; rod; transduction; adaptation; phosphodiesterase; vision

\section{Introduction}

Light-activated rhodopsin $\left(\mathrm{Rh}^{*}\right)$ catalyzes exchange of GTP for GDP on the transducin $\alpha$ subunit $\left(\mathrm{T}_{\alpha}\right) ; \mathrm{T}_{\alpha} \mathrm{GTP}$ then activates phosphodiesterase6 (PDE), which hydrolyzes cGMP and reduces the current entering the photoreceptor outer segment (Fain, 2003; Burns and Arshavsky, 2005). Response decay requires termination of all of these reactions: $\mathrm{Rh}^{\star}$ by phosphorylation by rhodopsin kinase and binding of arrestin; PDE by hydrolysis of $\mathrm{T}_{\alpha} \mathrm{GTP}$ to $\mathrm{T}_{\alpha} \mathrm{GDP}$ facilitated by the GTPase activating protein (GAP) complex consisting of regulator of G-protein signaling 9 (RGS9), G $\beta 5$, and R9AP; and resynthesis of cGMP by guanylyl cyclase. One of these steps is sufficiently slow to limit the rate of response decay, and its time constant $\tau_{\mathrm{D}}$ can be obtained from a

Received June 29, 2007; revised Dec. 12, 2007; accepted Jan. 7, 2008.

This work was supported by the Foundation Fighting Blindness, Burroughs-Wellcome Fund, Irma T. Hirschl Trust, Dennis W. Jahnigen Award of the American Geriatrics Society, Joel Hoffman Fund, Charles Culpeper Scholarship, Crowley Research Fund, Gale and Richard Siegel Stem Cell Fund, Schneeweiss Stem Cell Fund, Barbara and Donald Jonas Family Fund, Eye Surgery Fund of the Columbia College of Physicians and Surgeons, Bernard Becker Association of University Professors in Ophthalmology, Research to Prevent Blindness, and National Institutes of Health (NIH) Grant K08-EY004081 (S.H.T.); by the Pennsylvania Lion's Sight Preservation Foundation, the Martin and Florence Hafter Chair of Pharmacology, and NIH Grant EY11522 (A.M.D.); and by NIH Grant EY01844 (G.L.F.). We thank Margery Fain for help with figures and Daniel Tranchina for much useful discussion.

Correspondence should be addressed to Prof. Gordon L. Fain, Department of Physiological Science, University of California Los Angeles, 3836 Life Sciences, Los Angeles, CA 90095-1606. E-mail: gfain@ucla.edu. DOI:10.1523/JNEUROSCI.2973-07.2008

Copyright $\odot 2008$ Society for Neuroscience $\quad 0270-6474 / 08 / 282064-11 \$ 15.00 / 0$ plot of the length of time the response remains in saturation $\left(T_{\text {sat }}\right)$ versus the log of the light intensity (Pepperberg et al., 1992).

Krispel et al. (2006) have recently shown that the value of $\tau_{\mathrm{D}}$ is strongly correlated with the expression of the GAP complex proteins and therefore with the rate of $\mathrm{T}_{\alpha} \mathrm{GTP}$ hydrolysis. This important observation and other evidence (Sagoo and Lagnado, 1997; Tsang et al., 2006) indicate that turnoff of PDE is rate limiting for the return of the response to bright flashes. Krispel et al. (2006) further showed that the time constant for decay of the dim flash response $\left(\tau_{\mathrm{REC}}\right)$ also decreases with increasing GAP expression. The values of $\tau_{\mathrm{D}}$ and $\tau_{\mathrm{REC}}$ are correlated over a wide range in GAP overexpressing and underexpressing animals (Krispel et al., 2006), and also in mice with guanylate cyclaseactivating protein-1 (GCAP-1) Y99C, PDE $\gamma$ T35A and T22A/ T35A, and rhodopsin G90D mutations (supplemental Fig. 1, available at www.jneurosci.org as supplemental material).

In salamander, background light accelerates $\tau_{\mathrm{REC}}$ but has been reported to have little effect on the value of $\tau_{\mathrm{D}}$ (Pepperberg et al., 1992; Nikonov et al., 2000). This poses a dilemma, because it indicates either that $\tau_{\mathrm{D}}$ and $\tau_{\mathrm{REC}}$ are not as closely correlated as the results from mouse would seem to indicate (supplemental Fig. 1, available at www.jneurosci.org as supplemental material) or that mouse rods and salamander rods do not respond to background light in an identical manner. We resolved this dilemma by recording from mouse rods in darkness and in background light (Fain et al., 2007) and show that $\tau_{\mathrm{D}}$ in mammals does indeed 
decrease during adaptation to steady background light. Furthermore, both the decrease in $\tau_{\mathrm{REC}}$ and in $\tau_{\mathrm{D}}$ during light adaptation are absent in PDE $\gamma$ T35A rods, which lack the threonine 35 phosphorylation site of the PDE $\gamma$ subunit (Tsang et al., 2007). Our results indicate that rods have a novel mechanism of light adaptation, which regulates the rate of $\alpha$ GTP hydrolysis. This mechanism may be principally responsible for acceleration of response decay in backgrounds; by decreasing the integration time of the rod response in bright light, it may also make an important contribution to the regulation of receptor sensitivity. Because GAP complexes play an important role in turnoff of metabotropic synaptic receptors in the CNS (Zachariou et al., 2003; SanchezBlazquez et al., 2005), our experiments may reveal a new mechanism of signal transduction of general significance.

\section{Materials and Methods}

Animals. Wild-type (WT) mice were of the C57BL/6 and MF1 strains and were obtained from The Jackson Laboratory (Bar Harbor, ME). Methods for producing PDE $\gamma$ T35A and T22A/T35A mice on a PDE $\gamma$ knock-out background have been described previously (Tsang et al., 2007). Mice were kept in cyclic light ( $12 \mathrm{~h}$ on/12 h off) and used in accordance with the Policy for the Use of Animals in Neuroscience Research of the Society for Neuroscience. The lengths of the outer segments of WT and T22A/ T35A rods were not significantly different, and both were $\sim 10 \%$ longer than rods of T35A animals (Tsang et al., 2007); no corrections were made for this difference in plots of flash intensity or current magnitude. Previous experiments show that both T35A and T22A/T35A rods express normal levels of PDE $\gamma$ and of the PDE $\alpha$ and $\beta$ catalytic subunits, as well as of rhodopsin, $\mathrm{T}_{\alpha}$, rhodopsin kinase, RGS9, and guanylyl cyclase 2D (Tsang et al., 2007).

Identification of transgenic mice. DNA was isolated from tail tips or liver samples of T35A and T22A/T35A animals by homogenizing the tissue, digesting extensively with proteinase $\mathrm{K}$, and extracting with phenol. DNAs were analyzed by PCR. The transgenic alleles generated $1.1 \mathrm{~kb}$ fragments with forward (GAATTCCCAAGAGGACTCTGGG) and reverse (ATGGTGTATGAGCGGCG) primers in standard PCR conditions. The mice were also tested for the absence of the $P d e 6 b^{r d l}$ mutation (Pittler and Baehr, 1991). Selected genomic DNA was amplified for sequencing to confirm the presence of the mutant alleles with standard methodology (Tsang et al., 2007).

$\mathrm{Ca}^{2+}$ dependence of guanylyl cyclase in T35A rods. Determinations of the $\mathrm{Ca}^{2+}$ dependence of guanylyl cyclase in Figure $5 C$ were performed as described previously (Olshevskaya et al., 2004; Woodruff et al., 2007) with minor modifications. In brief, dark-adapted WT (MF1) and T35A mouse retinas 6-8 weeks of age were freeze thawed with liquid nitrogen and then homogenized under infrared illumination on ice in $250 \mu \mathrm{l}$ of $120 \mathrm{~mm} \mathrm{KCl}, 60 \mathrm{~mm}$ 3-( $N$-morpholino)-propanesulfonic acid (MOPS), $\mathrm{pH}$ 7.2, $10 \mathrm{~mm} \mathrm{NaCl}, 4.6 \mathrm{~mm} \mathrm{MgCl}_{2}, 0.2 \mathrm{~mm}$ ATP, $50 \mu \mathrm{m}$ zaprinast, $50 \mu \mathrm{M}$ dipyridamole, $20 \mu \mathrm{g} / \mathrm{ml}$ leupeptin, and $20 \mu \mathrm{g} / \mathrm{ml}$ aprotinin. Each $20 \mu \mathrm{l}$ assay reaction contained $1 \mathrm{~mm}$ GTP, $1 \mu \mathrm{Ci}\left[\alpha-{ }^{32} \mathrm{P}\right] \mathrm{GTP}, 0.1 \mu \mathrm{Ci}\left[8-{ }^{3} \mathrm{H}\right]$ cGMP (PerkinElmer, Emeryville, CA), and 4 mM cGMP, 0.3 mM ATP, 2.5 mм $\mathrm{MgCl}_{2}, 30 \mathrm{~mm}$ MOPS, pH 7.2, $5 \mathrm{~mm} \mathrm{NaCl}$, and $60 \mathrm{~mm} \mathrm{KCl}$, plus 25 $\mu \mathrm{M}$ each of zaprinast and dipyridamole, $1 \mathrm{U}$ of creatine phosphokinase, $10 \mathrm{~mm}$ creatine phosphate, and $2 \mathrm{~mm} \mathrm{Ca}^{2+} / \mathrm{EGTA}$ buffer at the desired free $\mathrm{Ca}^{2+}$ concentrations. The reaction was initiated by adding retinal homogenate and then continued for $12 \mathrm{~min}$ at $30^{\circ} \mathrm{C}$ under infrared illumination; it was stopped by heating at $95^{\circ} \mathrm{C}$ for $2 \mathrm{~min}$. The products of the reaction were analyzed by thin-layer chromatography on polyethyleneimine cellulose-coated fluorescent plates (Dizhoor et al., 1995).

Suction-electrode recordings. Methods for recording responses of mouse rods have been given previously (Woodruff et al., 2002, 2003; Tsang et al., 2007). Animals between 2 and 6 months of age were dark adapted typically for $5 \mathrm{~h}$ but for at least $3 \mathrm{~h}$ in a light-tight box. Rods were perfused at $37^{\circ} \mathrm{C}$ with bicarbonate-buffered physiological solution containing amino acids and nutrients. Data were filtered at $30 \mathrm{~Hz}(8$ pole, Bessel) and sampled at $100 \mathrm{~Hz}$. Flashes of $500 \mathrm{~nm}$ light, $20 \mathrm{~ms}$ in duration, were attenuated to different light levels by absorptive neutral density filters. At dim intensities, 10-20 individual responses presented at $5 \mathrm{~s}$ intervals were averaged to obtain mean flash responses. At medium intensities, 5-10 responses were averaged, and the interflash interval was increased to $10 \mathrm{~s}$. At bright intensities above saturation for the rods, only three to five responses were averaged, and the interflash interval was increased to 15-20 s. A $500 \mathrm{~nm}$ light was also used for steps of light and backgrounds. Other information about the details of response presentation are given in the figure legends. Unless otherwise stated, errors are given as SEM (SE). Curve fitting and plotting of data were done with the program Origin (OriginLab, Northampton, MA).

Measurements of free $\mathrm{Ca}^{2+}$ concentration. Calcium was measured as described previously (Woodruff et al., 2002, 2007). In brief, photoreceptors and retinal pieces were exposed for $30 \mathrm{~min}$ at room temperature to $10 \mu \mathrm{M}$ Fluo-5F AM and then perfused at $37^{\circ} \mathrm{C}$ with bicarbonate-buffered DMEM as for suction-electrode recordings. We illuminated rods with $488 \mathrm{~nm}$ laser light from an argon gas laser, focused as a $10 \mu \mathrm{m}$ diameter spot on the outer segment. To minimize dye bleaching, we attenuated the intensity of the laser to $2-5 \times 10^{10}$ photons $\mu \mathrm{m}^{-2} \mathrm{~s}^{-1}$ with reflective neutral density filters. We recorded the temperature of the perfusate within $0.5 \mathrm{~mm}$ of the rod with a miniature thermocouple and a digital thermometer to adjust the binding constant of the dye. We calibrated the intracellular concentration of $\mathrm{Ca}^{2+}$ in darkness and after illumination using the Michaelis-Menten equation, $\left[\mathrm{Ca}^{2+}\right]=K_{\mathrm{D}}\left(F-F_{\min } / F_{\max }-\right.$ $F$ ), where $K_{\mathrm{D}}$ is the temperature-adjusted dissociation constant of the dye- $\mathrm{Ca}^{2+}$ binding, $F$ is the measured fluorescence at the beginning of the recording or at steady state in the light, and $F_{\min }$ and $F_{\max }$ are the fluorescence minimum (in low $\mathrm{Ca}^{2+}$ ) and fluorescence maximum (in high $\mathrm{Ca}^{2+}$ ). We determined $F_{\text {min }}$ by exposing the rod first to zero-Ca ${ }^{2+}$ solution containing $10 \mu \mathrm{M}$ of the $\mathrm{Ca}^{2+}$ ionophore ionomycin, plus $140 \mathrm{~mm}$ $\mathrm{NaCl}, 3.6 \mathrm{~mm} \mathrm{KCl}, 3.08 \mathrm{~mm} \mathrm{MgCl}_{2}, 2.0 \mathrm{~mm}$ EGTA, and 3.0 mM HEPES, pH 7.4. We then determined $F_{\max }$ by exposing the rod to high $\mathrm{Ca}^{2+}$ solution ( $50 \mathrm{~mm} \mathrm{CaCl}_{2}, 3.6 \mathrm{~mm} \mathrm{KCl}, 3.0 \mathrm{~mm}$ HEPES, $140 \mathrm{~mm}$ sucrose, $\mathrm{pH}$ $7.4)$.

\section{Results \\ Background light decreases sensitivity and accelerates response decay of WT mouse rods}

In Figure 1, we show responses averaged from six WT rods in darkness and in the presence of four background illuminations, each to flashes of a constant intensity of 160 photons $\mu \mathrm{m}^{-2}$, or $\sim 80 \mathrm{Rh}^{\star}$ per rod (from an estimated collecting area of 0.5 ) (Field and Rieke, 2002). We used a constant flash intensity in this experiment to stimulate the same number of rhodopsins per rod in darkness and in each of the backgrounds, and we used this particular flash intensity so that responses with satisfactory signalto-noise can be recorded even in the brightest background. Responses on the left give actual photocurrents, with the black trace the response in darkness repeated in each of the four panels, and the red traces the responses in the presence of steady illumination, the intensity of which in units of photons $\mu \mathrm{m}^{-2} \mathrm{~s}^{-1}$ is given as the number in the top right of each panel. The peak amplitudes of the responses to the constant intensity flash decrease progressively with increasing background intensity, as we (Fan et al., 2005) and others (Mendez et al., 2001; Makino et al., 2004) have observed previously for mouse rods.

In Figure 1, in the panels to the right, we normalized the responses in darkness and in each of the backgrounds to the same peak response amplitude, which we set equal to one. As in salamander rods (Baylor et al., 1979; Nikonov et al., 2000), responses in the presence of the background decay more rapidly than does the response to the same flash intensity recorded when the rods are dark adapted. We fitted the declining phase of the normalized responses in the presence of the background to a single exponential decay function; these are shown in the insets to the right in Figure 1. We began the fit at a normalized photocurrent of 0.5 , because the flash intensity we used nearly saturated 
the responses in the dark and in the dimmest background, and we wished to avoid any effect of response compression on the fit to the waveform. The time constant decreased with increasing background light, in this sample of rods, from $290 \mathrm{~ms}$ in the dimmest background (and $296 \mathrm{~ms}$ in darkness) to $138 \mathrm{~ms}$ in the brightest.

\section{Background light also decreases the} value of the rate-limiting time constant To determine the effect of background light on the rate-limiting time constant $\tau_{\mathrm{D}}$, we recorded from a group of rods the response to a series of brief saturating flashes for each cell both in darkness and in the presence of a steady light. Responses averaged from nine cells are illustrated in Figure 2 for flashes of the same intensities in darkness $(A)$ and in the presence of a background of 1350 photons $\mu \mathrm{m}^{-2} \mathrm{~s}^{-1}(B)$. The background light reduced the time the response remained in saturation for each of the flashes. A horizontal line was drawn at a criterion level of $75 \%$ of the maximum value of the photocurrent, and the time in saturation, $T_{\text {sat }}$, was calculated as the time required after the presentation of the flash for the response to decay to this criterion value. These values are plotted in Figure $2 \mathrm{C}$ as a function of the natural logarithm of the flash intensity, and the slope of the best linear fit is an estimate of $\tau_{\mathrm{D}}$, the rate-limiting time constant for the decay of the response (Pepperberg et al., 1992). The best-fitting line through the means in Figure $2 C$ had a value of $231 \mathrm{~ms}$ in darkness and $170 \mathrm{~ms}$ in the presence of the background, indicating that this background intensity reduced $\tau_{\mathrm{D}}$ in WT rods by $\sim 25 \%$. The values of $\tau_{\mathrm{D}}$ were estimated by linear regression for each of the rods in this experiment independently, giving (mean $\pm \mathrm{SE}$ ) $238 \pm 8 \mathrm{~ms}$ in darkness and $159 \pm 7 \mathrm{~ms}$ in the presence of the background. The value in steady light is significantly smaller ( $p=0.01$ level; one-tailed Student's $t$ test).

In Figure $2 D$, we show results of a second series of experiments from six rods, for each of which we measured the time in saturation in darkness as in Figure $2 \mathrm{~A}$ and in steady light as in Figure $2 B$ but at the brighter background intensity of 4090 photons $\mu \mathrm{m}^{-2} \mathrm{~s}^{-1}$. In this sample of rods, $\tau_{\mathrm{D}}$ was $168 \mathrm{~ms}$ for the dark-adapted responses, less than with the rods of Figure $2 C$. This is typical of the variability in response kinetics, which we and others have observed from WT mouse rods in different animals even of the same strain, and emphasizes the importance of making measurements of $\tau_{\mathrm{D}}$ both in darkness and in the presence of the background from the same cells. The best-fitting value of $\tau_{\mathrm{D}}$ in Figure $2 D$ in the presence of the background was only $78 \mathrm{~ms}$, less than half that for these rods in the dark. The values of $\tau_{D}$ were again estimated by linear regression for each of the rods in this experiment independently, giving (mean \pm SE) $171 \pm 7 \mathrm{~ms}$ in darkness and $75 \pm 5 \mathrm{~ms}$ in the presence of the background. The value in steady light is significantly smaller $(p=0.0004$ level; one-tailed Student's $t$ test). These experiments show that background light reduces the rate-limiting time constant for the decay of the response in mouse rods, and that the extent of the reduction is greater for brighter backgrounds.

\section{Modulation of response waveform by background light is greatly reduced or eliminated in $\mathrm{PDE} \gamma \mathrm{T} 35 \mathrm{~A}$ rods}

Because the rate-limiting time constant of a WT mouse rod is likely to reflect the rate of T $\alpha \mathrm{GTP}$ hydrolysis and turning off of the PDE (Krispel et al., 2006), the results in Figures 1 and 2 appear to indicate that background light produces a modulation of T $\alpha$ GTP hydrolysis, perhaps by altering the action of one or more of the GAP proteins. We examined a possible role for phosphorylation of a member of the GAP complex, the PDE $\gamma$ protein. PDE $\gamma$ is known to contribute to the rate of PDE turnoff (Tsang et al., 1998; Arshavsky et al., 2002) and to show light-dependent phosphorylation at two sites: threonine 22 (Tsuboi et al., 1994a,b; Hayashi et al., 2000; Matsuura et al., 2000; Paglia et al., 2002) and threonine 35 (Udovichenko et al., 1994; Xu et al., 1998; Paglia et al., 2002). We have shown previously that replacement of either of these threonines with alanines produces significant changes in the time course of rod response decay (Tsang et al., 2007), and in rods with the T35A mutation, the rate-limiting time constant $\tau_{\mathrm{D}}$ is increased.

The T35A mutation also alters the effect of background light on rod response waveform. In Figure 3, we show mean responses of five rods to constant intensity flashes in darkness and in the presence of steady background light. The protocol for this exper- 

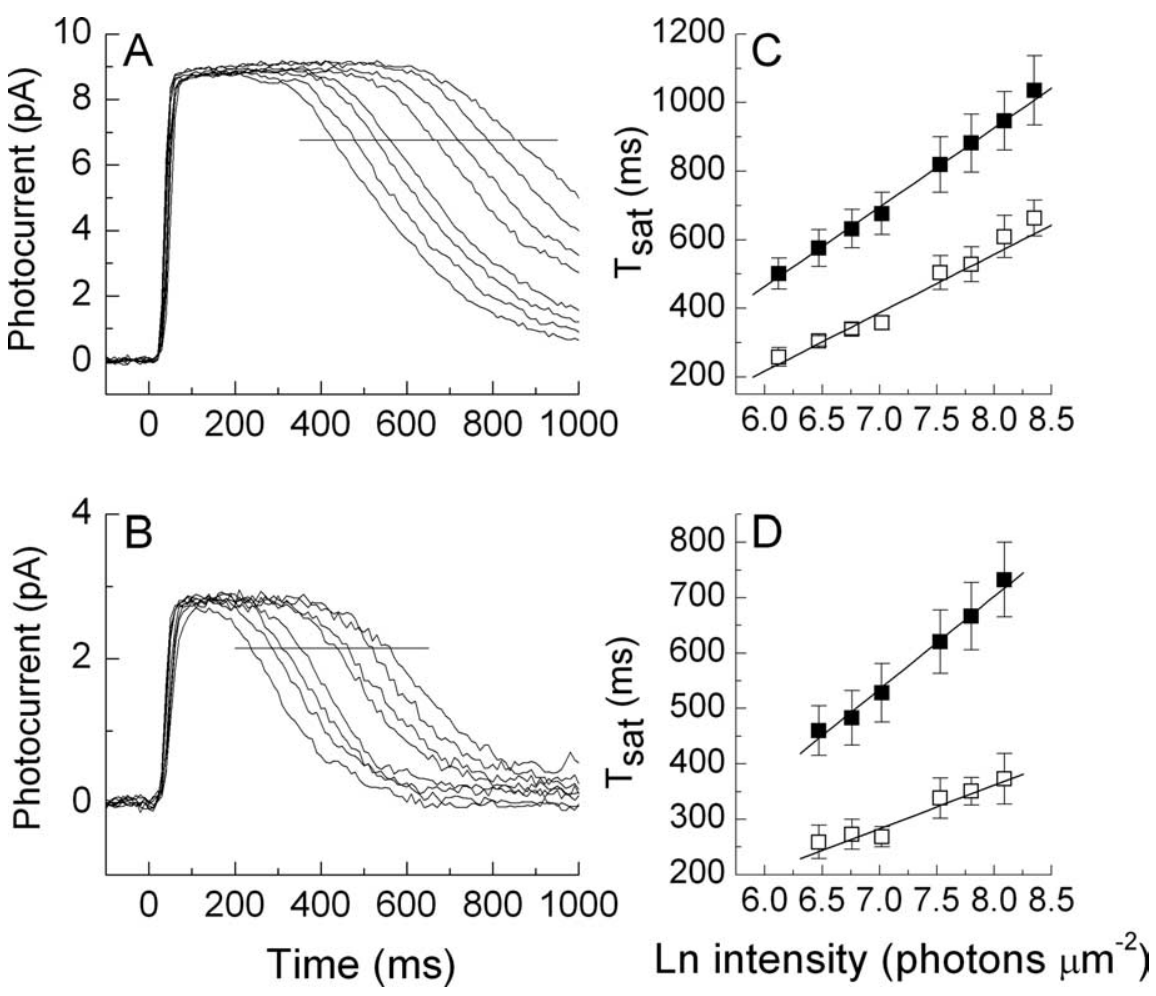

Figure 2. Pepperberg plots for WT rods in darkness and in the presence of background light. $\boldsymbol{A}, \boldsymbol{B}$, We show mean responses to five $20 \mathrm{~ms}$ flashes each for the same nine rods in darkness $(\boldsymbol{A})$ and in the presence of a steady background intensity of 1350 photons $\mu \mathrm{m}^{-2} \mathrm{~s}^{-1}(\boldsymbol{B})$ for the same series of eight flash intensities of $453,646,863,1120,1870,2430,3250$, and 4430 photons $\mu \mathrm{m}^{-2}$. The interval between flashes was $7 \mathrm{~s}$. The horizontal line marks the level of $75 \%$ of peak response amplitude. $\boldsymbol{C}$, Plot of time in saturation as a function of flash intensity for the rods of $\boldsymbol{A}$ and $\boldsymbol{B}$. For each rod at each flash intensity, we measured the time between the beginning of the flash and the recovery of the photocurrent to the value indicated by the horizontal lines in $\boldsymbol{A}$ and $\boldsymbol{B}$; this is equivalent to the time necessary to reopen $25 \%$ of the channels. These values $\left(T_{\text {sat }}\right)$ were plotted as a function of flash intensity in darkness (filled squares) and in the presence of the steady 1350 photons $\mu \mathrm{m}^{-2} \mathrm{~s}^{-1}$ background (open squares). Error bars are $S E$. The lines drawn through the data are the best linear fits and give estimates of the rate-limiting time constant $\tau_{\mathrm{D}}$; these are $231 \mathrm{~ms}$ in darkness and $170 \mathrm{~ms}$ in the background. $\boldsymbol{D}$, Plot similar to $C$ but for a different group of seven rods in darkness and at a background intensity of 4090 photons $\mu \mathrm{m}^{-2} \mathrm{~s}^{-1}$. Linear fits give estimated values for $\tau_{\mathrm{D}}$ of $168 \mathrm{~ms}$ in darkness and 78 $\mathrm{ms}$ in the background.

iment was identical to that in Figure 1, except that the flash and background intensities were made greater than for WT rods, because the flash sensitivity of T35A rods is lower than that of WT (see Fig. $8 C, D$ ), primarily as a result of less efficient activation of PDE catalytic activity in the T35A receptors (Tsang et al., 2007). The records to the left in Figure 3 show that presentation of the background light produces a decrease in the amplitude of the response, indicating a decrease in flash sensitivity as in WT rods. When the responses are normalized, however, there is little or no effect of the background light on the time course of response decay (Fig. 3, right).

In the experiments of Figure 4, we used a different protocol to investigate the effects of background light on response decay. A steady background or "light step" was first given for $10 \mathrm{~s}$, followed immediately by a brief flash of fixed saturating intensity (Fain et al., 1989). Previous experiments have shown that in WT mouse rods, the background accelerates the decline of the response to the saturating intensity, and the brighter the background, the greater the acceleration (Burns et al., 2002; Makino et al., 2004). We show a similar result in Figure $4 A$. However, when we repeated this experiment with T35A rods, the effect of the background was much smaller (Fig. 4B).

The small effect of background light on the time course of decay of T35A rods to a saturating flash in the records of Figure
$4 B$ bears some resemblance to the results of Makino et al. (2004) on rods lacking recoverin. We therefore measured recoverin levels in the T35A rods using Western blots, as shown in Figure 5, $A$ and $B$. The methods for these experiments are given in the figure. Figure $5 A$ shows that there was little difference in the expression of recoverin in T35A and WT rods. Similar measurements are given in Figure $5 B$ for T22A/ $\mathrm{T} 35 \mathrm{~A}$ rods, the responses of which to the step-flash protocol are given below (Fig. $9 B)$. Densitometric measurements from the gels gave levels of recoverin for T35A, which were $83.2 \pm 5.5 \%$ those of WT, which is mostly the result of the $10 \%$ decrease in the outer segment length of the $\mathrm{T} 35 \mathrm{~A}$ rods. Recoverin levels in $\mathrm{T} 22 \mathrm{~A} / \mathrm{T} 35 \mathrm{~A}$ retinas were $99.2 \pm 9.8 \%$ those of WT.

\section{Modulation of the rate-limiting time constant is also affected by the PDE $\gamma$ T35A mutation}

The effect of background light on the ratelimiting time constant $\tau_{\mathrm{D}}$ is also altered in T35A rods. In Figure 6, we show mean measurements of $T_{\text {sat }}$ as a function of flash intensity as in Figure 2, $C$ and $D$, but for six $\mathrm{T} 35 \mathrm{~A}$ rods, in darkness and in a background of intensity 1350 photons $\mu \mathrm{m}^{-2}$ $\mathrm{s}^{-1}$. This was the brightest background for which measurements of this kind could be made, because T35A rods saturated prematurely (Fig. $7 B$ ). The small shift of the light-adapted values of $T_{\text {sat }}$ along the intensity axis indicates a small decrease in the magnitude of the PDE activity evoked by the flashes. The best-fitting straight lines in Figure 6 , however, gave a value of $\tau_{\mathrm{D}}$ of 448 $\mathrm{ms}$ in darkness and $466 \mathrm{~ms}$ in the presence of the background. The values of $\tau_{\mathrm{D}}$ estimated by linear regression for each of the rods independently gave (mean \pm SE) $439 \pm 10 \mathrm{~ms}$ in darkness and $471 \pm 11 \mathrm{~ms}$ in the presence of the background. These are not significantly different (a one-tailed $t$ test returned a probability of $0.29)$.

\section{PDE $\gamma$ T35A mutation produces premature saturation of the} rod response in bright backgrounds

Because responses of rods with the PDE $\gamma$ T35A mutation show little acceleration of response decay in background light, it might be expected that the sensitivity of the rod would saturate prematurely in steady illumination. No change would occur in the integration time of the single-photon response as the background intensity was increased, and the responses of the photons would sum to produce a larger change in circulating current in bright light in T35A rods than would occur in WT receptors. The results in Figure 7 confirm this expectation. Here, we plotted in Figure $7 A$ (filled squares) the mean flash sensitivity of nine WT rods as a function of background intensity; the solid line through the data is the Weber-Fechner equation as follows:

$$
\frac{S_{F}}{S_{F}^{D}}=\frac{I_{0}}{I_{0}+I_{B}},
$$


where $S_{F}$ is the flash sensitivity of the rod, $S_{F}^{D}$ is the flash sensitivity in darkness, $I_{B}$ is the intensity of the background, and $I_{0}$ is a constant. We used the best-fitting value for $I_{0}$ of 30 photons $\mu \mathrm{m}^{-2} \mathrm{~s}^{-1}$, similar to the one we used previously for WT mouse rods (Fan et al., 2005).

Figure $7 B$ shows similar results for T35A rods. The open circles give mean measurements of flash sensitivity. Because T35A rods are less sensitive than WT rods in part as the result of less efficient activation of PDE activity (Tsang et al., 2007), brighter background light is required to reduce sensitivity below its value in darkness. The solid line is a fit of Equation 1 to the first three backgrounds; $I_{0}$ for T35A rods was 160 photons $\mu \mathrm{m}^{-2} \mathrm{~s}^{-1}$ or more than five times greater than for WT rods. The fit with the Weber-Fechner function is satisfactory for the first three backgrounds, but sensitivity is lower than this function would predict at the background of 1350 photons $\mu \mathrm{m}^{-2} \mathrm{~s}^{-1}$, and at a background of 4090 photons $\mu \mathrm{m}^{-2} \mathrm{~s}^{-1}$, no response could be recorded from the T35A rods. This is indicated by the open circle with the downward pointing triangle below it, which gives an upper limit calculated from the minimum detectable response averaged from a series of 10-20 flashes in our system $(\sim 0.2 \mathrm{pA})$ and the brightest flash intensity we used in the experiment. WT rods did give measurable responses in this background (Fig. 2D), although the background intensity was effectively much brighter for WT rods because of their greater efficacy in activating PDE (Tsang et al., 2007).

The dashed curve in Figure $7 B$ is the prediction of the change in sensitivity of the T35A rods if it were produced only by saturation of the rod by steady light. The sensitivity would then decrease according to the following:

$$
\frac{S_{F}}{S_{F}^{D}}=\exp \left(-\frac{I_{B} S_{F}^{D} t_{i}}{i_{\max }}\right),
$$

where the $t_{i}$ is the integration time of the small-amplitude response, and $i_{\max }$ is the maximum value of the photocurrent (Mendez et al., 2001). The small difference between the sensitivity measurements and this curve especially at the brighter background intensities shows that the T35A mutation has removed much of sensitivity regulation in the rod.

\section{Response-intensity functions for WT and T35A rods}

In Figure 8, we compare response-intensity curves for steps and flashes from both WT and T35A rods. Representative waveforms for flashes were given by Tsang et al. (2007), their Figure 2. Waveforms of responses to steps are given to the left in Figure 8 as mean normalized responses from all of the WT $(A)$ and T35A $(B)$ rods from which step responses were recorded. Responses were normalized before averaging so that responses of different peak amplitude gave equal weight to the average. For Figure $8, C$ and $D$, response amplitudes for both flashes and steps were obtained from the same 9 WT rods and 14 T35A rods, which formed part of the sample of cells used for parts $A$ and $B$. The data have been fitted with exponential saturation functions (Lamb et al., 1981) of the following form:

$$
i=i_{\max }[1-\exp (-k I)]
$$

where $i$ is the photocurrent, $i_{\max }$ is the maximum value of the photocurrent, $I$ is the flash or step intensity, and $k$ is a constant. Values for $k$ are given in the figure legend. This function provides an adequate fit to the data for WT rods for flashes; the curve for steps gives a less satisfactory fit, because the data appear to rise more gradually as a function of intensity, as others have observed previously (Fain et al., 1989). As a result, the best-fitting curve for steps indicates a lower saturating current for steps than for flashes, although the actual values of the responses to the steps continue to rise beyond the value predicted by the curve.

For the T35A rods, Equation 3 gives a satisfactory fit for responses to both flashes and steps. The ratio of the values of $k$ predicts an integration time for T35A rods of $\sim 290 \mathrm{~ms}$, smaller than the actual calculated value of the integration time for the dark-adapted small-amplitude response from this sample of rods ( $\sim 430 \mathrm{~ms})$. The discrepancy is, however, much smaller than for the WT rods: the integration time predicted from the values of $k$ for steps and flashes is only $\sim 70 \mathrm{~ms}$, whereas the actual measured integration time of the dark-adapted flash response for the WT 


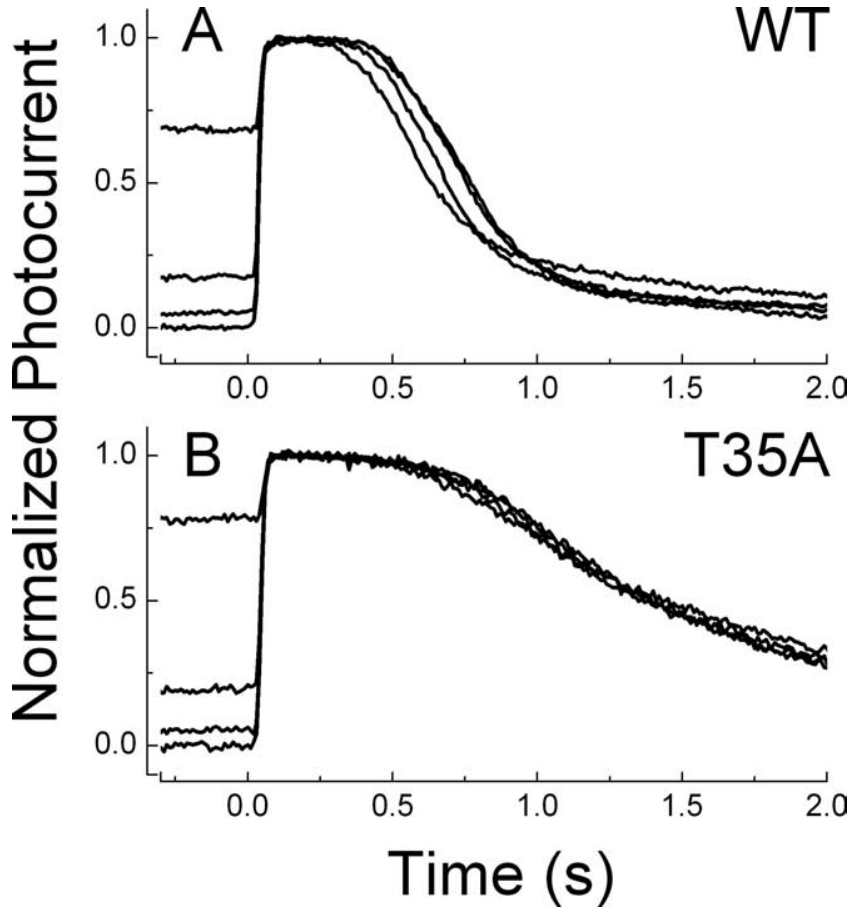

Figure 4. Step-flash protocol. Rods were either kept in the dark or exposed to background light for $10 \mathrm{~s}$ at intensities of 13,120 , and 1350 photons $\mu \mathrm{m}^{-2} \mathrm{~s}^{-1}$. Immediately after cessation of background, rods were exposed to $20 \mathrm{~ms}$ flash of 2430 photons $\mu \mathrm{m}^{-2}$, bright enough to close all of the channels and saturate the response even in the presence of the brightest background. $A$, WT rods. Traces are means from 10 rods; for each rod, five flashes were given without background and then four flashes after each of the three backgrounds. Each trace is the average of 50 (dark) or 40 (background) individual responses. Responses were normalized to a peak amplitude of one and averaged; rods were allowed to recover for $30 \mathrm{~s}$ between stepflashes exposures. $\boldsymbol{B}, \mathrm{T} 35 \mathrm{~A}$ rods. Protocol for experiment as in $\boldsymbol{A}$, but data were averaged from nine rods.

rods of Figure $8 D(\sim 310 \mathrm{~ms})$ was of the order of four times greater.

When the response-intensity curves for flashes and steps are compared between WT and T35A rods, the T35A rods can be seen to be less sensitive to flashes but almost as sensitive as WT to steps. The smaller sensitivity to flashes has been shown previously to be mostly the result of less efficient activation of PDE (Tsang et al., 2007). The T35A rods are nearly as sensitive as WT to steps, however, because they have a more prolonged integration time than WT rods (Tsang et al., 2007). Responses to steps in T35A rods also rise more steeply as intensity is increased, reflected by the better fit to Equation 3, in part because the integration time of the rod is not reduced in the presence of steady illumination (Fig. 3 ). This has the result that the dynamic range of the T35A rods is smaller than WT rods.

\section{$\mathrm{Ca}^{2+}$ feedback in $\mathrm{T} 35 \mathrm{~A}$ rods}

Much of adaptation in rods is thought to be produced by the fall of $\mathrm{Ca}^{2+}$ during illumination, which alters the rate of guanylyl cyclase by means of the GCAPs (Fain et al., 2001). Because sensitivity regulation is greatly altered by the T35A mutation (Figs. $7 B$, 8 ), we investigated whether $\mathrm{Ca}^{2+}$ feedback could still regulate cyclase in these rods. Our previous experiments (Tsang et al., 2007) showed that levels of guanylyl cyclase were normal in T35A rods. Using methods described previously (Olshevskaya et al., 2004; Woodruff et al., 2007), we measured cyclase activity as a function of free $\mathrm{Ca}^{2+}$ concentration in both WT and T35A retinas. The results in Figure $5 C$ show that the guanylyl cyclase of
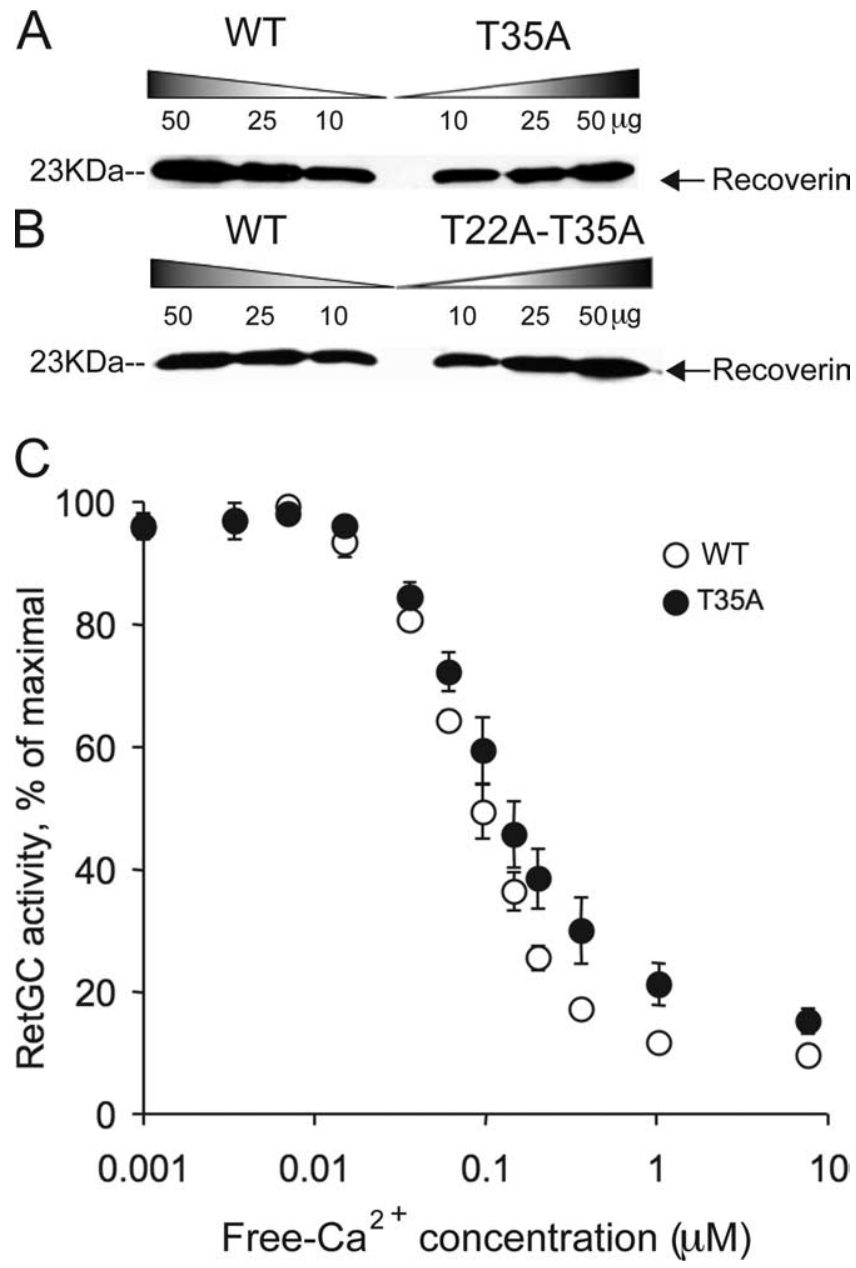

Figure 5. $\quad A, B$, Proteins from mutant and control retinal extract were separated by electrophoresis on a $6.5-9.5 \%$ acrylamide $/ 1.5 \%$ cross-linker polyacrylamide gel as described previously (Tsang et al., 2007). Proteins were then transferred to $0.2 \mu \mathrm{m}$ polyvinylidene difluoride membranes (Bio-Rad Laboratories, Hercules, $(A)$ overnight at $4 \mathrm{~V} / \mathrm{cm}$. Membranes were blocked in 3\% BSA in $500 \mathrm{~mm} \mathrm{NaCl}, 20 \mathrm{~mm}$ Tris, pH 7.6, and 0.1\% Tween 20. Proteins were detected with a polyclonal recoverin antibody (Dizhoor et al., 1992), used at 1:50,000 dilution. Immunoblot analysis of the expression of recoverin in T35A single, T22A-T35A double mutant, and WT control retinal extracts normalized for protein content is shown. Size marker is indicated at the left. Levels of recoverin are nearly the same in mutants and controls. $\mathrm{C}_{,} \mathrm{Ca}^{2+}$ dependence of guanylyl cyclase activity as a function of free $\mathrm{Ca}^{2+}$ concentration for WT rods (open symbols) and T35A rods (closed symbols) (mean \pm SD). Maximal levels of cyclase activity for WT and

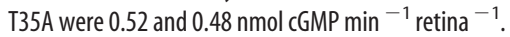

T35A rods had a similar dependence on $\mathrm{Ca}^{2+}$ to that of WT rods over the physiological range of $\mathrm{Ca}^{2+}$ [from $\sim 50-250 \mathrm{nM}$ (Woodruff et al., 2007)]. There was at most a small change in the slope of the relation, resulting in slightly greater cyclase activity in T35A rods than in WT rods at the higher $\mathrm{Ca}^{2+}$ concentrations.

We also made laser-spot measurements of free $\mathrm{Ca}^{2+}$ concentration in T35A rods as in the study by Woodruff et al. (2002). In rods preloaded with the fluorescent indicator dye Fluo-5F, the fluorescence declined during saturating illumination according to two exponential time constants; the best fit to the mean waveform of the fluorescence decrease from seven rods gave values of 61 and $352 \mathrm{~ms}$, somewhat shorter than those reported previously for WT rods [159s and $508 \mathrm{~ms}$ (Woodruff et al., 2002)]. Our previous experiments have shown that the dark resting free $\mathrm{Ca}^{2+}$ of the rod varies linearly with the current density of the outer segment (Matthews and Fain, 2003; Woodruff et al., 2007). Because the currents are smaller in T35A rods than in WT rods (Fig. 


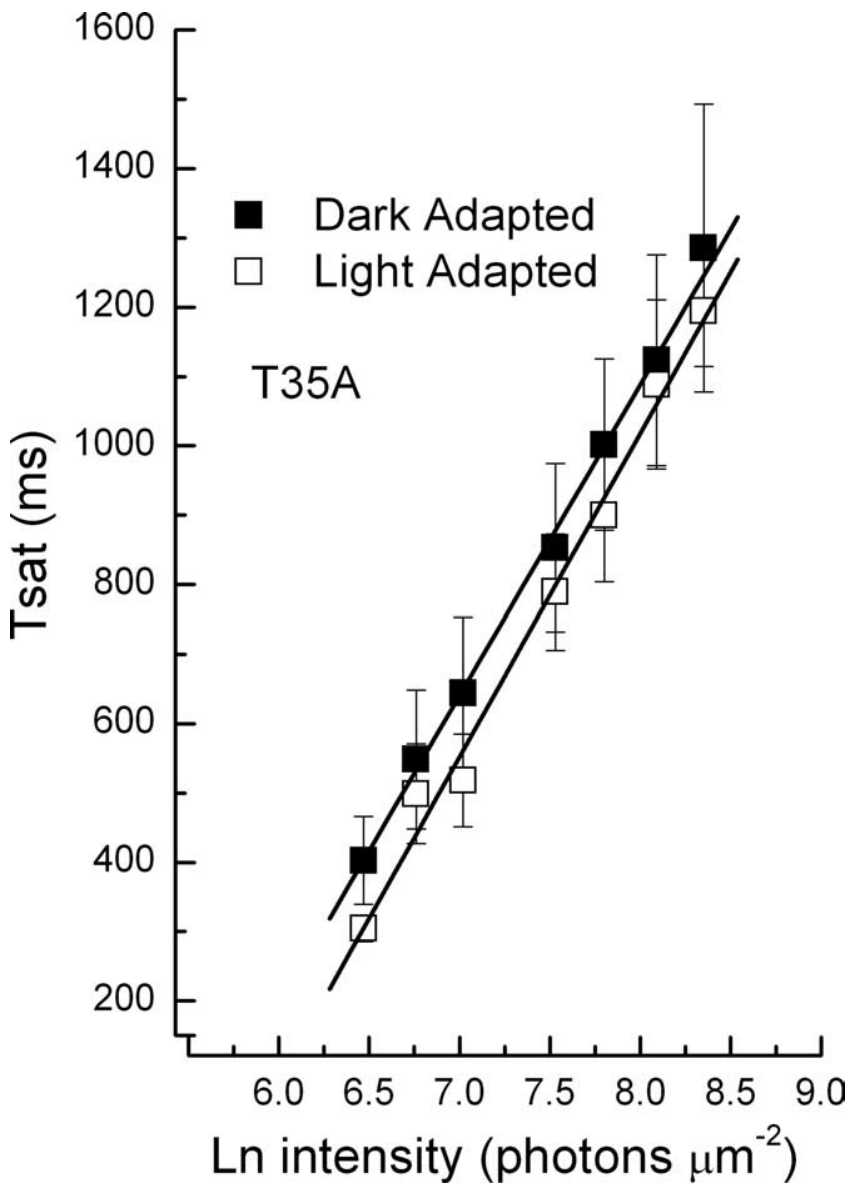

Figure 6. Pepperberg plots for PDE $\gamma \mathrm{T} 35 \mathrm{~A}$ rods. $T_{\text {sat }}$ is shown as a function of natural $\log (\mathrm{Ln})$ of light intensity as in Figure 2, C and D. Data points give mean values of $T_{\text {sat }}$ measured as in Figure 2 for seven rods in darkness (filled squares) and in the presence of background light of 1350 photons $\mu \mathrm{m}^{-2} \mathrm{~s}^{-1}$. Linear fits give values for $\tau_{\mathrm{D}}$ of $448 \mathrm{~ms}$ in darkness and $466 \mathrm{~ms}$ in the presence of background light.

$8 C, D)$ and the $\mathrm{T} 35 \mathrm{~A}$ rod outer segments only $10 \%$ shorter (Tsang et al., 2007), the current density of T35A rods is of the order of $75 \%$ that of WT rods, and we would expect the dark resting $\mathrm{Ca}^{2+}$ to be commensurately smaller. Measurements from six T35A rods gave a mean dark $\mathrm{Ca}^{2+}$ of $162 \pm 54 \mathrm{~nm}(\mathrm{SE}), \sim 68 \%$ of the dark value in WT rods of $240 \mathrm{~nm}$ (Woodruff et al., 2007). The concentration of $\mathrm{Ca}^{2+}$ in the light was $38 \pm 4 \mathrm{nM}$ in T35A rods, not significantly different from the light value in WT rods (46 \pm $10 \mathrm{~nm}$ ) (Woodruff et al., 2007). These measurements show that a significant fraction, although not all of the WT dynamic range of cyclase modulation, can occur in the T35A rods.

\section{Light adaptation is nearly normal in $\mathrm{PDE} \gamma \mathrm{T} 22 \mathrm{~A} / \mathrm{T} 35 \mathrm{~A}$ rods}

The data in Figures 4-8 suggest that replacement of threonine with alanine at the T35 site greatly reduces or eliminates modulation of PDE turnoff by background illumination. One possible explanation of these results is that phosphorylation of the T35 site regulates GAP activity, but it is also possible that removal of a phosphate group in this region of the PDE $\gamma$ protein, which between residues 20 and 40 contains seven basic lysine and arginine residues and is highly charged, produces an alteration in the conformation of the protein, which in some way hinders or masks GAP modulation. An important control for our experiments, therefore, is an examination of animals that lack both the T22 and T35 sites for phosphorylation, because our previous experiments

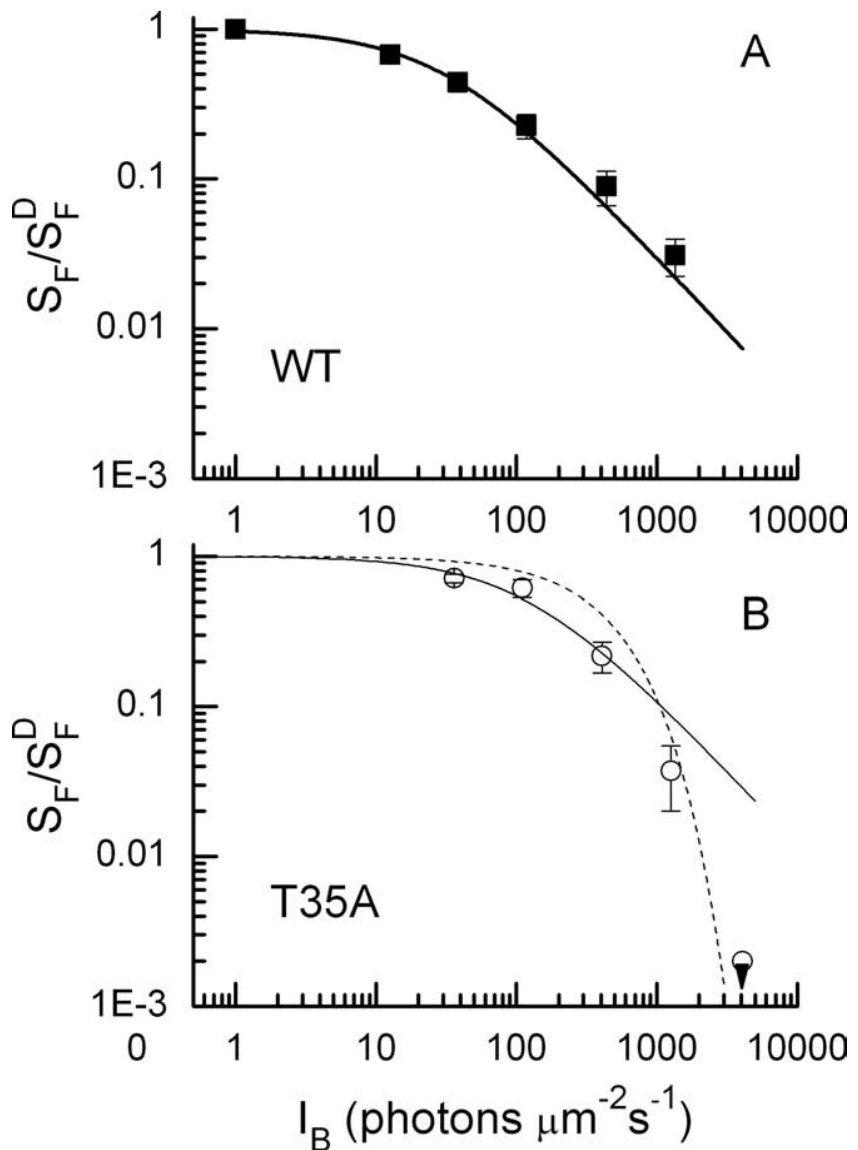

Figure 7. Mean relative sensitivity as a function of $\log _{10}$ of the background intensity. Flash sensitivities $\left(S_{F}\right)$ were determined for each rod by recording 5-10 small amplitude (threshold) responses and dividing the mean peak amplitude by the flash intensity. $S_{F}^{D}$ is the flash sensitivity in darkness. $A$, Averages of nine WT rods (filled squares). The solid line is best-fitting WeberFechner function given by Equation 1 with $I_{0}=30$ photons $\mu \mathrm{m}^{-2} \mathrm{~s}^{-1}$. $\boldsymbol{B}$, Averages of eight PDE $\gamma$ T35A rods (open circles). For T35A rods at a background of 4090 photons $\mu \mathrm{m}^{-2} \mathrm{~s}^{-1}, \mathrm{no}$ response could be recorded; the open circle with the downward pointing triangle indicates upper limit calculated from the minimum detectable response averaged from a series of $10-20$ flashes in our system $(\sim 0.2 \mathrm{pA})$ and the brightest flash intensity we used in the experiment. The solid line is best-fitting Weber-Fechner function given by Equation 1 with $I_{0}=160$ photons $\mu \mathrm{m}^{-2} \mathrm{~s}^{-1}$. The dotted line is prediction of increment saturation given by Equation 2, calculated with $S_{F}^{D}=0.08 \mathrm{pA}$ photon ${ }^{-1} \mu \mathrm{m}^{2}, t_{i}=365 \mathrm{~ms}$, and $i_{\max }=7 \mathrm{pA}$. Values for $S_{F}^{D}$ and $i_{\max }$ were somewhat smaller for these rods than reported throughout this paper but are within the range of variability observed for $\mathrm{T} 35 \mathrm{~A}$ rods.

have shown that rod response decay is much less affected in PDE $\gamma$ T22A/T35A rods than in the T35A receptors (Tsang et al., 2007).

The results of these experiments are given in Figure 9. In $A$, we show mean responses of six rods to $20 \mathrm{~ms}$ flashes of a constant intensity of 17 photons $\mu \mathrm{m}^{-2}$, in darkness and in the presence of two backgrounds of intensities 38 and 440 photons $\mu \mathrm{m}^{-2} \mathrm{~s}^{-1}$. Responses have been normalized to the same peak amplitude to compare time courses of decay; unnormalized waveforms are given in the inset of Figure $9 A$. The most slowly decaying response recorded in darkness could be fitted with a single exponential with time constant of decay $\left(\tau_{\text {REC }}\right)$ of $227 \mathrm{~ms}$, whereas the best-fitting values of $\tau_{\mathrm{REC}}$ for the responses in the two backgrounds were 219 and $175 \mathrm{~ms}$. The acceleration of the decay time of the light response is in contrast to our results for the T35A rods (Fig. 3). Results from experiments with the step-flash protocol were also quite different for T22A/T35A rods (Fig. 9B) and T35A rods (Fig. $4 B$ ) but similar to those from WT receptors (Fig. $4 A$ ).

In Figure $9 C$, we show the effect of a steady background of 
intensity 1350 photons $\mu \mathrm{m}^{-2} \mathrm{~s}^{-1}$ on the relationship between $T_{\text {sat }}$ and flash intensity. We measured in darkness and in the presence of the background for each of six T22A/T35A rods the time of recovery of the response to $25 \%$ of the maximum value of the circulating current as in Figure 2, A and $B$, and the data were plotted as in Figure $2 C$. For this sample of rods, the bestfitting value of the slope $\tau_{\mathrm{D}}$ in darkness was $208 \mathrm{~ms}$, intermediate between the values for the WT rods in Figure 2, $C$ and $D$; the value of $\tau_{\mathrm{D}}$ in the background light was 170 $\mathrm{ms}$. The values of $\tau_{\mathrm{D}}$ were estimated by linear regression for each of the rods in this experiment, giving (mean \pm SE) $207 \pm 6$ $\mathrm{ms}$ in darkness and $177 \pm 5 \mathrm{~ms}$ in the presence of the background; however, a onetailed Student's $t$ test indicated that this difference was not significant at the 0.05 level.

Finally, in Figure 9D, we plotted the relative sensitivity of six T22A/T35A rods as a function of the intensity of the background. For the T22A/T35A rods, $I_{0}$ from Equation 1 had a best fitting value of 100 photons $\mu \mathrm{m}^{-2} \mathrm{~s}^{-1}$. The sensitivity at the background intensity of 4090 photons $\mu \mathrm{m}^{-2} \mathrm{~s}^{-1}$ lies somewhat below the Weber-Fechner curve, but at this background intensity, no responses could be recorded at all from the T35A rods (Fig. 7B). We conclude from the results of this figure that T22A/T35A rods adapt to background
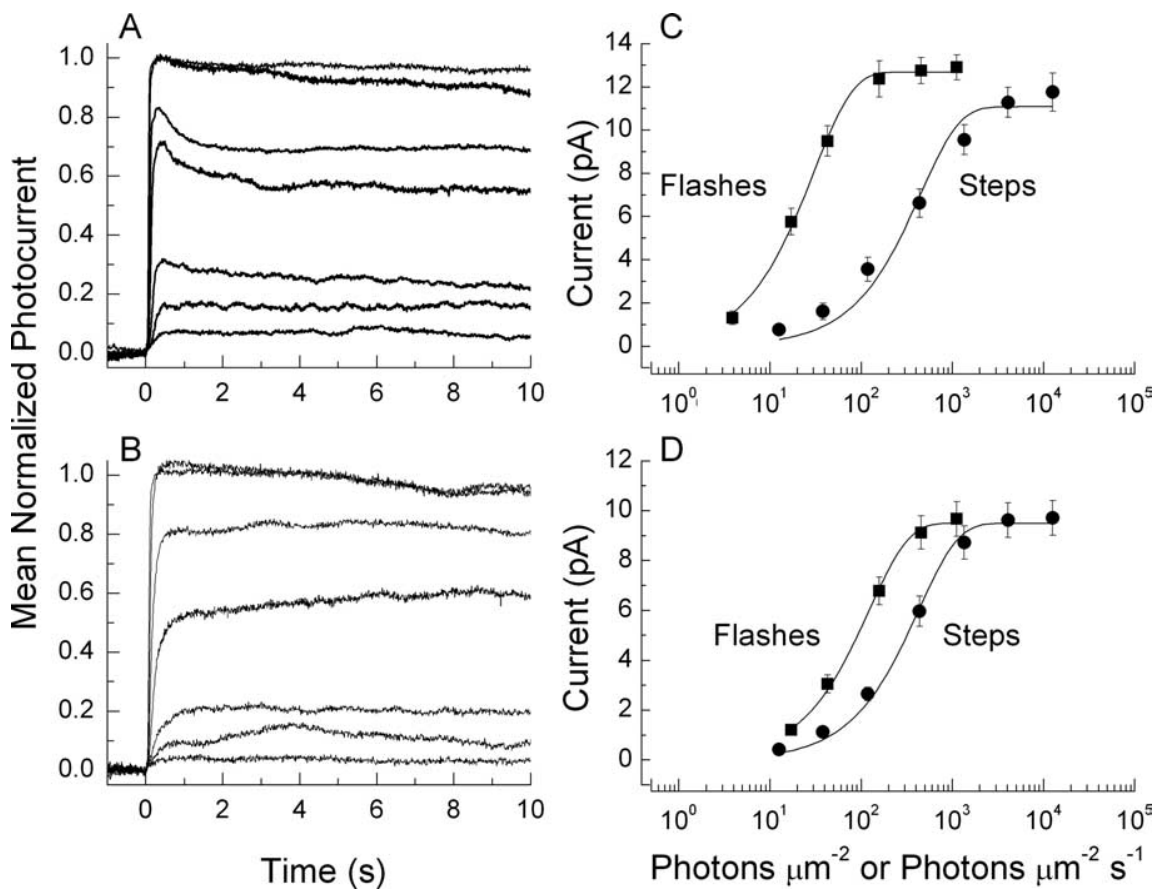

Figure 8. Responses to steps and response-intensity relationships for flashes and steps for WT and T35A rods. $\boldsymbol{A}, \boldsymbol{B}$, Normalized responses of WT $(\boldsymbol{A})$ and T35A $(\boldsymbol{B})$ rods to steps of increasing intensity of values $12.6,38.2,118,438,1350,4090$, and 12,600 photons $\mu \mathrm{m}^{2} \mathrm{~s}^{-1}$. Data were first normalized for each rod to the maximum amplitude of the response for that rod and then averaged at each intensity, for WT from between 13 and 28 rods and for T35A from between 8 and 17 rods. C, D, Responseintensity curves for flashes and steps. Amplitudes were calculated for each rod from peak photocurrents of 3-5 20 ms flashes or values of photocurrents just before termination of five successive $10 \mathrm{~s}$ light steps. For each rod, we recorded responses to the complete series of intensities shown in the figure for both flashes and steps, and plotted values are means of nine WT rods and 14 T35A rods. C, Responses of WT rods to flashes and steps. Fits are to Equation 3, with $k$ equal to 0.033 photon ${ }^{-1} \mu \mathrm{m}^{2}$ for flashes and 0.0022 photon ${ }^{-1} \mu \mathrm{m}^{2} \mathrm{~s}$ for steps. $\boldsymbol{D}$, Responses of T35A rods to flashes and steps. Fits are to Equation 3 with $k$ equal to 0.0082 photon ${ }^{-1} \mu \mathrm{m}^{2}$ for flashes and 0.0023 photon ${ }^{-1} \mu \mathrm{m}^{2} \mathrm{~s}$ for steps.

lights in a nearly normal manner unlike the T35A rods. Thus, the effect of substitution of alanine for threonine at the T35 site of PDE $\gamma$ cannot be the result of the removal of phosphorylation per se but must rather be a consequence of a change in the conformation of the PDE $\gamma$ molecule.

\section{The T35A mutation does not remove adaptation after exposure to bright light}

The experiments of Figures 1 and 2 show that background light produces both an acceleration of the declining phase of the light response and a decrease in $\tau_{\mathrm{D}}$ in WT rods. Because Krispel et al. (2003a) have shown that prolonged exposure of WT mouse rods to bright light can also produce a transient acceleration of response turnoff, we used the T35A mutation to ask whether the mechanism of adaptation during steady backgrounds and after bright light exposure is the same. In the experiment of Figure 10, we show averaged responses of $11 \mathrm{~T} 35 \mathrm{~A}$ rods to a series of saturating flashes after a 3 min exposure to a light, the intensity of which was 4090 photons $\mu \mathrm{m}^{-2} \mathrm{~s}^{-1}$, similar to the intensity used by Krispel et al. (2003a) for WT rods. The black trace in the figure shows the mean response waveform before presentation of the 3 min exposure to a saturating flash, the intensity of which (1870 photons $\mu \mathrm{m}^{-2}$ ) was again similar to that used in the Krispel et al. (2003a) experiments. The colored traces were recorded to this same flash intensity at $27 \mathrm{~s}$ (red), $47 \mathrm{~s}$ (green), $67 \mathrm{~s}$ (blue), and $107 \mathrm{~s}$ (pink) after presentation of the bright light, and the peak amplitudes of all of the responses have been normalized to unity. The 3 min bright light exposure produced an acceleration of recovery of the response to the flash, and this effect gradually decayed over a period of 1-3 min. As in Figure $2, A$ and $B$, a horizontal line was drawn at a criterion level of $75 \%$ of the maximum value of the photocurrent, and the time in saturation, $T_{\text {sat }}$, was calculated for each of the responses as the time required for the response to decay to this criterion level. In the inset of Figure 10 , we plotted the values of $T_{\text {sat }}$ normalized to the value in darkness as a function of the time after presentation of the 3 min light exposure. The data have been fitted with a single exponential, the time constant of which (67 s) is similar to that observed previously by Krispel et al. (2003a) in WT rods.

The results in Figure 10 show that, after exposure to prolonged bright illumination, the time in saturation $T_{\text {sat }}$ is decreased and then recovers in T35A rods in a manner that is similar if not identical to that of WT rods. In a second series of recordings, we presented both steady background light (as in Fig. 3) and prolonged bright light exposure (as in Fig. 10) to the same T35A rods. We do not show these data, because there was excessive drift in the baseline, but the results were nevertheless clear. For these T35A rods, background light had no effect on the waveform of decay of the flash response, but exposure to prolonged bright illumination produced a decrease in $T_{\text {sat }}$, which decayed slowly back to its dark-adapted value. These experiments indicate that the mechanisms regulating response waveform during light adaptation to steady backgrounds and after prolonged bright light exposure are not the same.

\section{Discussion}

There are two principal results from our study. We have shown first that for WT mouse rods, background light decreases both the 
time constant of decay of the flash response $\left(\tau_{\mathrm{REC}}\right)$ and the rate-limiting time constant $\left(\tau_{\mathrm{D}}\right)$. In a second series of experiments, we have made the surprising discovery that in T35A rods, which lack one of the sites of PDE $\gamma$ phosphorylation, background lights have little or no effect on $\tau_{\mathrm{REC}}$ or $\tau_{\mathrm{D}}$. In a WT rod, $\tau_{\mathrm{D}}$ is known to reflect the rate of T $\alpha$ GTP hydrolysis and turnoff of PDE (Krispel et al., 2006), and $\tau_{\mathrm{D}}$ is very likely to do this in T35A rods as well, because mutations in $\operatorname{PDE} \gamma$ are much more likely to alter its interaction with the GAP complex (Burns and Arshavsky, 2005) than to affect rhodopsin lifetime (Fig. 5A) or guanylyl cyclase activity. Although rod responses can turn off even in the absence of the GAP proteins in RGS9 and G $\beta 5$ knock-out animals (Chen et al., 2000; Krispel et al., $2003 \mathrm{~b}$ ), the rate of the GAP-independent turnoff is much slower than turnoff in WT or $\mathrm{T} 35 \mathrm{~A}$ rods and is unlikely to contribute to the waveform of the WT or T35A light response or to the acceleration of the WT response during light adaptation.

Our results therefore argue for a novel mechanism of light adaptation in which background light modulates the rate of T $\alpha$ GTP hydrolysis by the GAP complex. This resolves the dilemma mentioned in the Introduction, because $\tau_{\mathrm{REC}}$ and $\tau_{\mathrm{D}}$, which are closely correlated with one another in GAP overexpressing and underexpressing animals (Krispel et al., 2006) and in a variety of other mutant mice (supplemental Fig. 1, available at www.jneurosci.org as supplemental material), continue to be closely correlated in WT rods in background light. Background light decreases both $\tau_{\mathrm{REC}}$ and $\tau_{\mathrm{D}}$ by the same mechanism, that is by acceleration of PDE turnoff, and modulation of T $\alpha \mathrm{GTP}$ hydrolysis is primarily responsible for the quickening of kinetics and improvement in temporal discrimination of the mammalian rod response during light adaptation.

The mechanism we are describing appears to be different from the one that produces decreases in $\tau_{\mathrm{REC}}$ and $\tau_{\mathrm{D}}$ after prolonged exposure to saturating illumination. Krispel et al. (2003a) showed that both $\tau_{\mathrm{REC}}$ and $\tau_{\mathrm{D}}$ are shortened after exposure to saturating light and then recover in 1-3 min after the light is turned off. We have done similar experiments on T35A rods (Fig. 10) as well as on T22A and T22A/T35A rods (Tsang et al., 2007). Prolonged exposure to saturating light in these rods also decreases $\tau_{\mathrm{REC}}$, which then recovers over approximately the same time course as the one described by Krispel et al. (2003a) for WT rods. Because the T35A mutation greatly perturbs adaptation of the rods to background light but has little effect on the acceleration of response decay after prolonged exposure to bright light, the two effects are unlikely to be produced in the same way.

We do not know why the acceleration of response turnoff in background light can no longer be observed in the T35A rods. The results in Figure 9 show that the effect of the mutation is not simply caused by removal of the T35 site of phosphorylation, because light adaptation is nearly normal in T22A/T35A rods that lack both phosphorylation sites. The T35A mutation might nevertheless produce a significant change in the conformation of the
$\operatorname{PDE} \gamma$, because removal of this phosphorylation site might perturb the insertion or removal of a large negative charge from a highly polar region of the PDE $\gamma$ subunit, and the resulting change in conformation may interrupt or mask modulation of PDE turnoff. Biochemical experiments indicate that the region between amino acids $24-45$ is essential for the control of PDE6 $\gamma$ of both the PDE $6 \alpha \beta$ core and the $\alpha$ subunit of transducin (Guo et al., 2005). Our experiments are therefore consistent with the notion that removal of a site of phosphorylation alters the conformation of PDE $\gamma$ sufficiently to affect either the rate of the GAPdependent hydrolysis of $\mathrm{T}_{\alpha} \mathrm{GTP}$ or the rebinding of PDE $\gamma$ back onto the catalytic sites of PDE $\alpha$ and $\beta$, but they do not exclude other possible mechanisms.

Our measurements show that the T35A mutation eliminates much of light adaptation in a mouse rod. Not only does the time course of decay fail to accelerate in the presence of background light (Figs. 3, 4B), but responses saturate prematurely, and sensitivity as a function of background light is better described for brighter background lights by response compression than the Weber law (Fig. 7B). We cannot exclude the possibility that changes in $\mathrm{Ca}^{2+}$ feedback contribute to these effects. Our experiments show that $\mathrm{Ca}^{2+}$ regulation of guanylyl cyclase is nearly the same in T35A rods and in WT rods (Fig. 5C), but the dark-resting $\mathrm{Ca}^{2+}$ concentration is $\sim 30 \%$ lower. We do not know the reason for the decrease in the dark free $\mathrm{Ca}^{2+}$ concentration. It is possible that it is caused by an increase in the basal activity of the PDE in T35A rods, but reports of the effects of PDE $\gamma$ phosphorylation on PDE activity are contradictory (Xu et al., 1998; Paglia et al., 2002) 


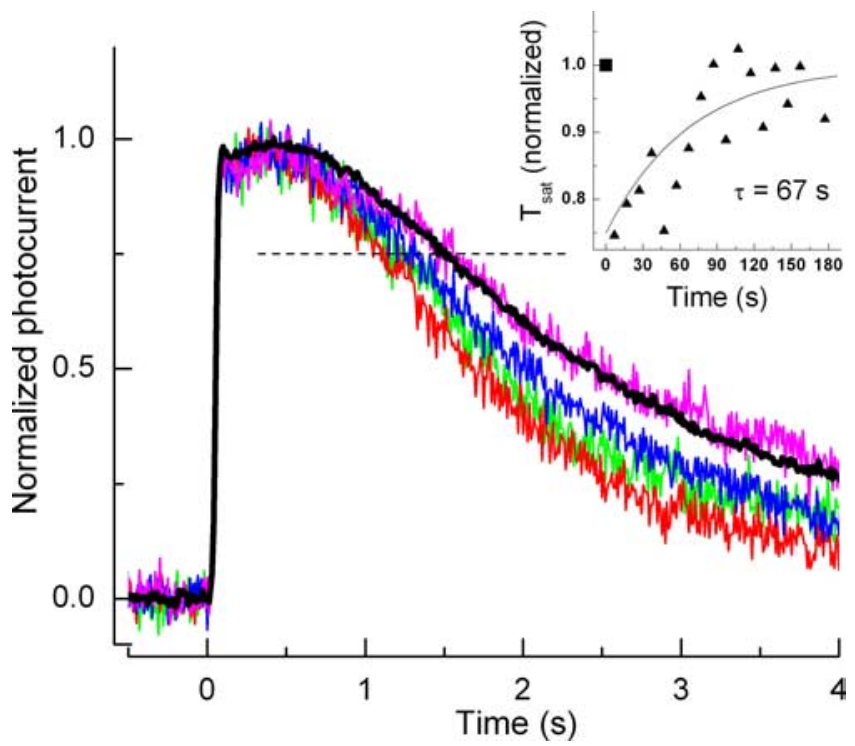

Figure 10. Each of 11 dark-adapted T35A rods were stimulated with five $20 \mathrm{~ms}$ flashes at a saturating intensity of 1870 photons $\mu \mathrm{m}^{-2}$, separated by a 10 s interflash interval. Each rod was then exposed to a saturating constant light of 4090 photons $\mu \mathrm{m}^{-2} \mathrm{~s}^{-1}$ for $3 \mathrm{~min}$. When the constant light was extinguished, $20 \mathrm{~ms}$ flashes of 1870 photons $\mu \mathrm{m}^{-2}$ were resumed at $7 \mathrm{~s}$ after termination of the 3 min exposure and continued each $10 \mathrm{~s}$ for a period of $3 \mathrm{~min}$. The black trace is the mean of the dark-adapted responses from the 11 T35A mouse rods normalized individually to their maximum amplitude; the response for each rod was obtained by averaging over the five flash presentations. The red, green, blue, and pink traces are from these same rods at $27,47,67$, and $107 \mathrm{~s}$ after the constant light was terminated. $T_{\text {sat }}$ was obtained from the time of recovery of the response to $25 \%$ of the dark current (horizontal dashed line). The inset gives $I_{\text {sat }}$ after exposure to 3 min illumination (triangles) normalized to its value in darkness (square) as a function of time after presentation of the 3 min exposure. The triangles have been fitted with a single exponential with a time constant of $67 \mathrm{~s}$.

and do not admit of a simple interpretation. Whatever its origin, the decrease in dark free $\mathrm{Ca}^{2+}$ might have the consequence that steady illumination would have smaller effects on guanylyl cyclase activity in T35A rods than in WT rods and be partly responsible for the marked inability of these cells to regulate sensitivity over all but a narrow range of backgrounds. A smaller dynamic range of cyclase activity could also contribute to the steeper shape of the response-intensity curve of the T35A rods to steps (Fig. $8 D)$.

It is nevertheless exceedingly unlikely that changes in $\mathrm{Ca}^{2+}$ feedback are entirely responsible for the phenomenology of the T35A mutation. The reduction in current density and free $\mathrm{Ca}^{2+}$ in a T35A rod is relatively small and should not prevent further acceleration of $\mathrm{Ca}^{2+}$ feedback and guanylyl cyclase rate when the free $\mathrm{Ca}^{2+}$ concentration is made even smaller by background light (compare Figs. 5C and 8D). Rods in which all of $\mathrm{Ca}^{2+}$ feedback is removed by the knocking out of the GCAP proteins have responses that decay more slowly and show much larger single-photon responses than do T35A rods (Mendez et al., 2001). Furthermore, the GCAP knock-out rods (unlike the T35A rods) continue to show a speeding up of response decay in background light (Burns et al., 2002). The separate roles of $\mathrm{Ca}^{2+}$ feedback and modulation of PDE turnoff in the light adaptation of mouse rods may become clearer when recordings are made from T35A rods that also lack the GCAP proteins. Such experiments are in progress.

Our results are at variance with a recently proposed mechanism of light adaptation for amphibian rods. In salamander, background light has been claimed to have little effect on the rate-limiting time constant $\tau_{\mathrm{D}}$ (Pepperberg et al., 1992; Nikonov et al., 2000), and the acceleration of decay of the rod response during light adaptation has been thought to occur not by modulation of PDE turnoff but rather by an increase in the rate of turnover of cGMP, produced by the increase in the basal rate of the PDE in the light and by GCAP-dependent acceleration of guanylyl cyclase (Nikonov et al., 2000). In mouse, in contrast, our experiments show that the rate-limiting time constant $\tau_{\mathrm{D}}$ is accelerated in background light (Fig. 2), and that modulation of PDE turnoff rather than the increase in cGMP turnover is primarily responsible for the acceleration of response decay. It is striking that background light has so little effect on the time course of response decay in T35A rods (Figs. 3,4B). The simplest explanation of this result is that the rate of cGMP turnover in a mouse rod is sufficiently rapid even in darkness that the photocurrent accurately tracks the change in PDE rate. The further increase in cGMP turnover in backgrounds might then have little or no effect on the rate of response decay. Modulation of T $\alpha \mathrm{GTP}$ hydrolysis may have evolved in mammalian photoreceptors to compensate for the higher basal turnover of cGMP, so that the integration time of the light response can continue to be maximal in darkness to sum responses near threshold, but can decrease as the ambient light intensity increases to improve temporal resolution when photon flux is no longer limiting.

Our experiments show that the activity of GAP proteins can be modulated. Although the biochemistry of this effect is presently unknown, the photoreceptor may provide a favorable preparation for additional analysis of the mechanism. RGS proteins and GAP complexes are known to participate in the turnoff of metabotropic cascades at synapses in the CNS (Zachariou et al., 2003; Sanchez-Blazquez et al., 2005) and have been implicated in the etiology of schizophrenia (Erdely et al., 2006; Seeman et al., 2007). It may be important to understand how GAP modulation occurs, because its mechanism may suggest new possibilities for modulating synaptic transmission in the CNS and for altering the course of neurological dysfunction.

\section{References}

Arshavsky VY, Lamb TD, Pugh Jr EN (2002) G proteins and phototransduction. Annu Rev Physiol 64:153-187.

Baylor DA, Lamb TD, Yau KW (1979) The membrane current of single rod outer segments. J Physiol (Lond) 288:589-611.

Burns M, Arshavsky V (2005) Beyond counting photons: trials and trends in vertebrate visual transduction. Neuron 48:387-401.

Burns ME, Mendez A, Chen J, Baylor DA (2002) Dynamics of cyclic GMP synthesis in retinal rods. Neuron 36:81-91.

Chen CK, Burns ME, He W, Wensel TG, Baylor DA, Simon MI (2000) Slowed recovery of rod photoresponse in mice lacking the GTPase accelerating protein RGS9-1. Nature 403:557-560.

Dizhoor AM, Ericsson LH, Johnson RS, Kumar S, Olshevskaya E, Zozulya S, Neubert TA, Stryer L, Hurley JB, Walsh KA (1992) The NH2 terminus of retinal recoverin is acylated by a small family of fatty acids. J Biol Chem 267:16033-16036.

Dizhoor AM, Olshevskaya EV, Henzel WJ, Wong SC, Stults JT, Ankoudinova I, Hurley JB (1995) Cloning, sequencing, and expression of a $24-\mathrm{kDa}$ $\mathrm{Ca}\left({ }^{2+}\right)$-binding protein activating photoreceptor guanylyl cyclase. J Biol Chem 270:25200-25206.

Erdely HA, Tamminga CA, Roberts RC, Vogel MW (2006) Regional alterations in RGS4 protein in schizophrenia. Synapse 59:472-479.

Fain GL (2003) Sensory transduction. Sunderland, MA: Sinauer.

Fain GL, Lamb TD, Matthews HR, Murphy RL (1989) Cytoplasmic calcium as the messenger for light adaptation in salamander rods. J Physiol (Lond) 416:215-243.

Fain GL, Matthews HR, Cornwall MC, Koutalos Y (2001) Adaptation in vertebrate photoreceptors. Physiol Rev 81:117-151

Fain GL, Woodruff ML, Tsang SH (2007) Decrease in sensitivity without acceleration of response decay in PDEgamma T35A mouse rods exposed 
to background illumination. Invest Ophthalmol Vis Sci 48:E-Abstract 2845.

Fan J, Woodruff ML, Cilluffo MC, Crouch RK, Fain GL (2005) Opsin activation of transduction in the rods of dark-reared Rpe65 knockout mice. J Physiol (Lond) 568:83-95.

Field GD, Rieke F (2002) Nonlinear signal transfer from mouse rods to bipolar cells and implications for visual sensitivity. Neuron 34:773-785.

Guo LW, Grant JE, Hajipour AR, Muradov H, Arbabian M, Artemyev NO, Ruoho AE (2005) Asymmetric interaction between rod cyclic GMP phosphodiesterase gamma subunits and alphabeta subunits. J Biol Chem 280:12585-12592.

Hayashi F, Matsuura I, Kachi S, Maeda T, Yamamoto M, Fujii Y, Liu H, Yamazaki M, Usukura J, Yamazaki A (2000) Phosphorylation by cyclindependent protein kinase 5 of the regulatory subunit of retinal cGMP phosphodiesterase. II. Its role in the turnoff of phosphodiesterase in vivo. J Biol Chem 275:32958-32965.

Krispel CM, Chen CK, Simon MI, Burns ME (2003a) Novel form of adaptation in mouse retinal rods speeds recovery of phototransduction. J Gen Physiol 122:703-712.

Krispel CM, Chen CK, Simon MI, Burns ME (2003b) Prolonged photoresponses and defective adaptation in rods of $\mathrm{G} \beta 5^{-1-}$ mice. J Neurosci 23:6965-6971.

Krispel CM, Chen D, Melling N, Chen YJ, Martemyanov KA, Quillinan N, Arshavsky VY, Wensel TG, Chen CK, Burns ME (2006) RGS expression rate-limits recovery of rod photoresponses. Neuron 51:409-416.

Lamb TD, McNaughton PA, Yau KW (1981) Spatial spread of activation and background desensitization in toad rod outer segments. J Physiol (Lond) 319:463-496.

Makino CL, Dodd RL, Chen J, Burns ME, Roca A, Simon MI, Baylor DA (2004) Recoverin regulates light-dependent phosphodiesterase activity in retinal rods. J Gen Physiol 123:729-741.

Matsuura I, Bondarenko VA, Maeda T, Kachi S, Yamazaki M, Usukura J, Hayashi F, Yamazaki A (2000) Phosphorylation by cyclin-dependent protein kinase 5 of the regulatory subunit of retinal cGMP phosphodiesterase. I. Identification of the kinase and its role in the turnoff of phosphodiesterase in vitro. J Biol Chem 275:32950-32957.

Matthews HR, Fain GL (2003) The effect of light on outer segment calcium in salamander rods. J Physiol (Lond) 552:763-776.

Mendez A, Burns ME, Sokal I, Dizhoor AM, Baehr W, Palczewski K, Baylor DA, Chen J (2001) Role of guanylate cyclase-activating proteins (GCAPs) in setting the flash sensitivity of rod photoreceptors. Proc Natl Acad Sci USA 98:9948-9953.

Nikonov S, Lamb TD, Pugh Jr EN (2000) The role of steady phosphodiesterase activity in the kinetics and sensitivity of the light-adapted salamander rod photoresponse. J Gen Physiol 116:795-824.

Olshevskaya EV, Calvert PD, Woodruff ML, Peshenko IV, Savchenko AB, Makino CL, Ho YS, Fain GL, Dizhoor AM (2004) The Y99C mutation in guanylyl cyclase-activating protein 1 increases intracellular $\mathrm{Ca}^{2+}$ and causes photoreceptor degeneration in transgenic mice. J Neurosci 24:6078-6085.

Paglia MJ, Mou H, Cote RH (2002) Regulation of photoreceptor phosphodiesterase (PDE6) by phosphorylation of its inhibitory gamma subunit re-evaluated. J Biol Chem 277:5017-5023.

Pepperberg DR, Cornwall MC, Kahlert M, Hofmann KP, Jin J, Jones GJ,
Ripps H (1992) Light-dependent delay in the falling phase of the retinal rod photoresponse. Vis Neurosci 8:9-18.

Pittler SJ, Baehr W (1991) Identification of a nonsense mutation in the rod photoreceptor cGMP phosphodiesterase $\beta$-subunit gene of the rd mouse. Proc Natl Acad Sci USA 88:8322-8326.

Sagoo MS, Lagnado L (1997) G-protein deactivation is rate-limiting for shut-off of the phototransduction cascade. Nature 389:392-395.

Sanchez-Blazquez P, Rodriguez-Munoz M, Montero C, Garzon J (2005) RGS-Rz and RGS9-2 proteins control mu-opioid receptor desensitisation in CNS: the role of activated Galphaz subunits. Neuropharmacology 48:134-150.

Seeman P, Ko F, Jack E, Greenstein R, Dean B (2007) Consistent with dopamine supersensitivity, RGS9 expression is diminished in the amphetamine-treated animal model of schizophrenia and in postmortem schizophrenia brain. Synapse 61:303-309.

Tsang SH, Burns ME, Calvert PD, Gouras P, Baylor DA, Goff SP, Arshavsky VY (1998) Role of the target enzyme in deactivation of photoreceptor $G$ protein in vivo. Science 282:117-121.

Tsang SH, Woodruff ML, Chen CK, Yamashita CY, Cilluffo MC, Rao AL, Farber DB, Fain GL (2006) GAP-independent termination of photoreceptor light response by excess $\gamma$ subunit of the c-GMPphosphodiesterase. J Neurosci 26:4472-4480.

Tsang SH, Woodruff ML, Janisch KM, Cilluffo MC, Farber DB, Fain GL (2007) Removal of phosphorylation sites of gamma subunit of phosphodiesterase6 alters rod light response. J Physiol (Lond) 579:303-312.

Tsuboi S, Matsumoto H, Yamazaki A (1994a) Phosphorylation of an inhibitory subunit of cGMP phosphodiesterase in Rana catesbeiana rod photoreceptors. II. A possible mechanism for the turnoff of cGMP phosphodiesterase without GTP hydrolysis. J Biol Chem 269:15016-15023.

Tsuboi S, Matsumoto H, Jackson KW, Tsujimoto K, Williams T, Yamazaki A (1994b) Phosphorylation of an inhibitory subunit of cGMP phosphodiesterase in Rana catesbeiana rod photoreceptors. I. Characterization of the phosphorylation. J Biol Chem 269:15024-15029.

Udovichenko IP, Cunnick J, Gonzalez K, Takemoto DJ (1994) Functional effect of phosphorylation of the photoreceptor phosphodiesterase inhibitory subunit by protein kinase C. J Biol Chem 269:9850-9856.

Woodruff ML, Sampath AP, Matthews HR, Krasnoperova NV, Lem J, Fain GL (2002) Measurement of cytoplasmic calcium concentration in the rods of wild- type and transducin knock-out mice. J Physiol (Lond) 542:843-854.

Woodruff ML, Wang Z, Chung HY, Redmond TM, Fain GL, Lem J (2003) Spontaneous activity of opsin apoprotein is a cause of Leber congenital amaurosis. Nat Genet 35:158-164.

Woodruff ML, Olshevskaya EV, Savchenko AB, Peshenko IV, Barrett R, Bush RA, Sieving PA, Fain GL, Dizhoor AM (2007) Constitutive excitation by Gly90Asp rhodopsin rescues rods from degeneration caused by elevated production of cGMP in the dark. J Neurosci 27:8805-8815.

Xu LX, Tanaka Y, Bonderenko VA, Matsuura I, Matsumoto H, Yamazaki A, Hayashi F (1998) Phosphorylation of the gamma subunit of the retinal photoreceptor CGMP phosphodiesterase by the cAMP-dependent protein kinase and its effect on the gamma subunit interaction with other proteins. Biochemistry 37:6205-6213.

Zachariou V, Georgescu D, Sanchez N, Rahman Z, DiLeone R, Berton O, Neve RL, Sim-Selley LJ, Selley DE, Gold SJ, Nestler EJ (2003) Essential role for RGS9 in opiate action. Proc Natl Acad Sci USA 100:13656-13661. 